\title{
Fine-tuning of hematopoietic stem cell homeostasis: novel role for ubiquitin ligase
}

\author{
Tomomasa Yokomizo and Elaine Dzierzak ${ }^{\mathbf{1}}$ \\ Department of Cell Biology, Erasmus Medical Center, 3000 CA Rotterdam, The Netherlands
}

\begin{abstract}
Homeostasis of hematopoietic stem cells (HSCs) is a tightly regulated process, controlled by intrinsic and extrinsic signals. Although a variety of molecules involved in HSC maintenance and self-renewal are known, it remains unclear how robust HSC homeostasis is achieved. In this issue of Genes \& Development, Rathinam and colleagues (pp. 992-997) report a new player in HSC homeostasis, c-Cbl ubiq-uitin ligase. They show that this E3 ubiquitin ligase acts as a negative regulator of cytokine signaling.
\end{abstract}

The E3 ubiquitin ligase c-Cbl is a member of the RING finger-type ubiquitin ligase $\mathrm{Cbl}$ (casitas B-cell lymphoma) family. It has been shown to interact with several tyrosine kinase receptors and other adaptor proteins to "finetune" lymphocyte antigen receptor signaling, mainly through ubiquitination (for review, see Duan et al. 2004). To study the role of c-Cbl in hematopoietic stem cells (HSCs), Rathinam et al. (2008) examined mice lacking $c$-Cbl. Surprisingly, they observed that the number of HSCs (CD34 ${ }^{-} \mathrm{Flt} 3^{-} \mathrm{LSK}$ or CD150+CD48- cells) was increased in the bone marrow of c-Cbl-deficient mice, and that c-Cbl-deficient HSCs were more competent than wild-type HSCs in reconstituting the hematopoietic system. Examination of another c-Cbl mutant mouse line, in which E3 ligase activity was ablated but the tyrosine kinase-binding domain was preserved, showed an almost identical HSC phenotype to that of c-Cbl-deficient HSCs. These results strongly suggest that ubiquitin-mediated protein degradation is important for HSC homeostasis.

What is the target substrate for c-Cbl in HSCs? Rathinam et al. (2008) observed accumulation of signal transducer and activator of transcription 5 (STAT5) and phosphorylated STAT5 (activated form) in c-Cbl-deficient HSCs, and proposed that STAT5 is a candidate target for ubiquitin-mediated degradation. STAT5 is an intracellular transducer of several hematopoietic-specific

[Keywords: Hematopoietic stem cells; c-Cbl; thrombopoietin; STAT5; self-renewal]

${ }^{1}$ Corresponding author.

E-MAIL e.dzierzak@erasmusmc.nl; FAX 31-10-704-4468.

Article is online at http://www.genesdev.org/cgi/doi/10.1101/gad.1669908. cytokine signaling pathways. Therefore, although there are many targets of c-Cbl (Duan et al. 2004), it is likely that STAT5 is a major target of c-Cbl in the context of HSC homeostasis.

\section{HSC homeostasis and cytokine signaling}

Many cytokines have been tested for their ability to stimulate self-renewal and expansion of HSCs in vitro. Thrombopoietin (TPO) and Stem Cell Factor (SCF) are recognized as important positive regulators of HSC self-renewal and expansion, although expansion has not been achieved thus far. The receptors for TPO and SCF- $-\mathrm{Mpl}$ and c-Kit, respectively-are expressed on transplantable HSCs (Ikuta and Weissman 1992; Solar et al. 1998; Adolfsson et al. 2001; Yoshihara et al. 2007), and mice with genetic mutations in TPO, SCF, c-Mpl, or c-Kit are reduced in HSC numbers (Russell 1979; Kimura et al. 1998; Qian et al. 2007). Interestingly, Rathinam et al. (2008) show that c-Cbl-deficient HSCs are hypersensitive to TPO. TPO-c-Mpl activates three downstream signaling pathways: mitogen-activated protein kinase (MAPK) (Rojnuckarin et al. 1999), phosphoinositide 3-kinase-Akt (PI3K-AKT) (Geddis et al. 2001), and Janus kinase (JAK)STAT3 and STAT5 (Dorsch et al. 1995; Drachman et al. 1995). Kato et al. (2005) reported that STAT5 activation was observed in HSCs (CD34-KSL cells) after TPO stimulation, and overexpression of STAT5 in HSCs enhanced their self-renewal activity ex vivo. Thus, it is likely that JAK-STAT is an important downstream pathway of TPO signaling for HSC maintenance. Consistent with this notion, HSCs lacking Lnk, an adaptor protein functioning as a negative regulator of several cytokine signaling pathways, show increased self-renewal capacity and an increased amount of phosphorylated STAT5 in the presence of TPO signaling (Ema et al. 2005; BuzaVidas et al. 2006; Seita et al. 2007). The phenotypes of c-Cbl-deficient HSCs resemble those of Lnk-deficient HSCs, showing both hypersensitivity to TPO and increased phosphorylated STAT5 (Rathinam et al. 2008). Although it is uncertain whether there is a direct relationship between Lnk and c-Cbl, Rathinam et al. (2008) clearly show that $\mathrm{c}-\mathrm{Cbl}$ modulates the c-Mpl-TPO-JAKSTAT signaling pathway in HSCs. 


\section{HSC maintenance in the bone marrow niche}

HSC self-renewal and differentiation are thought to be controlled through interactions with the bone marrow niche (for review, see Wilson and Trumpp 2006). In the bone marrow, HSCs are associated with osteoblasts, endothelial cells, or CXCL12 ${ }^{+}$reticular cells /Calvi et al. 2003; Zhang et al. 2003; Kiel et al. 2005; Sugiyama et al. 2006). Although it is still unclear why several distinct niches exist in the bone marrow, various molecules have been proposed to be involved in the signaling between HSCs and the niche (Wilson and Trumpp 2006). Among them, Angiopoietin-1, a ligand for the Tie-2 receptor, is expressed by osteoblasts in the bone marrow niche and is important for maintaining HSC quiescence (Arai et al. 2004). Notch signaling also has been proposed to be crucial for HSC expansion in the niche, since Notch1 and Jagged1 are expressed by HSCs and osteoblasts, respectively (Calvi et al. 2003), and inhibition of Notch signaling by a dominant-negative protein results in accelerated differentiation of HSCs in vitro and depletion of HSCs in vivo (Duncan et al. 2005). However, conditional deletion studies reveal that these molecules are dispensable for HSC maintenance in vivo (Mancini et al. 2005).

Until recently, it was unclear whether TPO signaling is involved in HSC maintenance within the bone marrow niche. However, Yoshihara et al. (2007) and Qian et al. (2007) reported that TPO is expressed by osteoblasts in the bone marrow niche and is involved in HSC quiescence and expansion. Given that c-Cbl-deficient mice have increased numbers of HSCs in the bone marrow and c-Cbl-deficient HSCs are hypersensitive to TPO (Rathinam et al. 2008), it is plausible that c-Cbl modulates the signal from TPO-producing osteoblasts in the bone marrow niche through the ubiquitination of STAT5. Of note, the JAK-STAT signaling pathway is also involved in blood cell homeostasis in Drosophila. Like the mouse bone marrow niche, a small cluster of cells in the primary lobe of the Drosophila lymph gland-termed the posterior signaling center-controls the balance between multipotent prohemocytes and differentiating hemocytes. In STAT mutant flies, increased hemocyte differentiation has been observed (Krzemien et al. 2007), implicating JAK-STAT signaling in the maintenance of undifferentiated hemocyte progenitors. Thus, the JAK-STAT signaling pathway may be evolutionally conserved in function, providing maintenance of stem cells within the niche.

While accumulating evidence indicates that interaction between stem cells and a niche is critical for stem cell maintenance, two recent studies have demonstrated that there is a competition between stem cells for niche occupancy. Jin et al. (2008) demonstrated that in Drosophila, bgcn and bam mutant germline stem cells (GSCs) push wild-type GSCs out of the niche because of their higher expression of E-cadherin. Similar stem cell competition has been observed in the mouse bone marrow niche. Czechowicz et al. (2008) showed that treatment with ACK2, an antibody that blocks c-Kit function, cleared host HSCs from the niche and enabled HSC en- graftment without irradiation. In addition, the number of HSCs in the bone marrow has been shown to correlate with the number of osteoblasts (Calvi et al. 2003). These results strongly suggest that the number of niches is limited. If so, where within the bone marrow environment are the surplus HSCs in c-Cbl-deficient mice localized? Or, in the steady-state bone marrow, are the niches not fully occupied by HSCs? One possibility is that c-Cbldeficient HSCs have a greater adhesive ability for the niches than wild-type HSCs and associate with "incomplete niches," thus resulting in higher numbers of HSCs in the bone marrow. Consistently, Rathinam et al. (2008) observe that c-Cbl-deficient HSCs are more competent than wild-type HSCs in bone marrow reconstitution. Further detailed and quantitative histological analysis of the bone marrow of c-Cbl-deficient mice may answer this question.

\section{Outside the bone marrow: HSC homeostasis in embryos}

During embryonic stages, HSCs are generated prior to the establishment of the bone marrow niches. It is still unclear whether the embryonic niches that maintain HSCs are equivalent to adult bone marrow niches. Stromal cell lines isolated from several embryonic HSC niches (aorta-gonad-mesonephros region and liver) have been shown to support the maintenance of adult bone marrow HSCs (Oostendorp et al. 2005; Durand et al. 2007). However, other studies indicate that the properties of HSCs differ between embryonic and adult stages, although it seems that they share the same embryonic origin (Göthert et al. 2005; Samokhvalov et al. 2007).

HSCs change from a rapidly proliferating state to a quiescent state between 3 and 4 wk after birth (Bowie et al. 2006). Moreover, conditional depletion of the Sox 17 transcription factor revealed that it is required for the maintenance of fetal and neonatal HSCs, but not adult HSCs (Kim et al. 2007). In contrast, Tie receptors are important for regulation of adult HSCs, but not fetal HSCs (Puri and Bernstein 2003). Sensitivity to cytokines is also different between HSCs from embryonic and adult stages. Fetal HSCs are more sensitive to SCF than adult HSCs despite the same expression level of c-Kit (Bowie et al. 2007). In addition, TPO is crucial for expansion of adult HSCs, but not fetal HSCs (Qian et al. 2007). To date, it is unknown what factors modulate the sensitivity to these cytokines. It is now worth considering the possibility that protein modifications like ubiquitination affect the sensitivity of HSCs to cytokines.

\section{Does aberrant control of ubiquitination lead to leukemia?}

It has been well documented that regulators of HSC maintenance are also involved in leukemic induction (for review, see Rizo et al. 2006). Although Rathinam et al. (2008) have not observed tumor formation in c-Cbl- 
deficient mice, it is possible that accumulation of STAT5 in c-Cbl-deficient HSCs increases susceptibility for leukemic transformation, since overexpression of STAT5 in HSCs induces myeloproliferative disease (Kato et al. 2005). In this regard, the study by Rathinam et al. (2008) might be extrapolated to other molecules like PTEN, TEL, and Gfil, which have been reported to be involved in both HSC homeostasis and leukemia (Akagi et al. 2004; Hock et al. 2004a,b; Yilmaz et al. 2006; O'Neil and Look 2007). These proteins are also ubiquitinated (Chakrabarti et al. 1999; Marteijn et al. 2007; Trotman et al. 2007; Wang et al. 2007). Thus, dysregulation of ubiquitin-mediated degradation may result in HSC exhaustion or tumor formation. Indeed, it has been reported that the PTEN protein level controlled by NEDD4-1 ubiquitin ligase influences its tumor suppressor activity (Trotman et al. 2007; Wang et al. 2007).

The study by Rathinam et al. (2008) now opens a new avenue for understanding the regulation of intracellular signaling and a further mechanism underlying HSC homeostasis. While researchers have looked previously to surface signaling molecules on HSCs to prospectively isolate and characterize HSCs, we should now begin to focus on the fine-tuning of intracellular signaling molecules by ubiquitination events inside HSCs. With the improvement of detection methods, it will be important to demonstrate the direct targets of ubiquitination in HSCs.

\section{Acknowledgments}

We acknowledge funding from the NIH, Netherlands Scientific Organization (NWO), and Dutch BSIK SCDD and DPTE programs, which supports research in our laboratory concerning the development of HSCs and their niches.

\section{References}

Adolfsson, J., Borge, O.J., Bryder, D., Theilgaard-Mönch, K., Astrand-Grundström, I., Sitnicka, E., Sasaki, Y., and Jacobsen, S.E. 2001. Upregulation of Flt3 expression within the bone marrow Lin $^{-} \mathrm{Sca}^{+}{ }^{+} \mathrm{c}-\mathrm{kit}^{+}$stem cell compartment is accompanied by loss of self-renewal capacity. Immunity 15: 659-669.

Akagi, K., Suzuki, T., Stephens, R.M., Jenkins, N.A., and Copeland, N.G. 2004. RTCGD: Retroviral tagged cancer gene database. Nucleic Acids Res. 32: D523-D527. doi: 10.1093/nar/ gkh013.

Arai, F., Hirao, A., Ohmura, M., Sato, H., Matsuoka, S., Takubo, K., Ito, K., Koh, G.Y., and Suda, T. 2004. Tie2/angiopoietin-1 signaling regulates hematopoietic stem cell quiescence in the bone marrow niche. Cell 118: 149-161.

Bowie, M.B., McKnight, K.D., Kent, D.G., McCaffrey, L., Hoodless, P.A., and Eaves, C.J. 2006. Hematopoietic stem cells proliferate until after birth and show a reversible phase-specific engraftment defect. J. Clin. Invest. 116: 2808-2816.

Bowie, M.B., Kent, D.G., Copley, M.R., and Eaves, C.J. 2007. Steel factor responsiveness regulates the high self-renewal phenotype of fetal hematopoietic stem cells. Blood 109: 5043-5048.

Buza-Vidas, N., Antonchuk, J., Qian, H., Månsson, R., Luc, S., Zandi, S., Anderson, K., Takaki, S., Nygren, J.M., Jensen, C.T., et al. 2006. Cytokines regulate postnatal hematopoietic stem cell expansion: Opposing roles of thrombopoietin and LNK. Genes \& Dev. 20: 2018-2023.

Calvi, L.M., Adams, G.B., Weibrecht, K.W., Weber, J.M., Olson, D.P., Knight, M.C., Martin, R.P., Schipani, E., Divieti, P., Bringhurst, F.R., et al. 2003. Osteoblastic cells regulate the haematopoietic stem cell niche. Nature 425: 841-846.

Chakrabarti, S.R., Sood, R., Ganguly, S., Bohlander, S., Shen, Z., and Nucifora, G. 1999. Modulation of TEL transcription activity by interaction with the ubiquitin-conjugating enzyme UBC9. Proc. Nat1. Acad. Sci. 96: 7467-7472.

Czechowicz, A., Kraft, D., Weissman, I.L., and Bhattacharya, D. 2008. Efficient transplantation via antibody-based clearance of hematopoietic stem cell niches. Science 318: 1296-1299.

Dorsch, M., Fan, P.D., Bogenberger, J., and Goff, S.P. 1995. TPO and IL-3 induce overlapping but distinct protein tyrosine phosphorylation in a myeloid precursor cell line. Biochem. Biophys. Res. Commun. 214: 424-431.

Drachman, J.G., Griffin, J.D., and Kaushansky, K. 1995. The c-Mpl ligand (thrombopoietin) stimulates tyrosine phosphorylation of Jak2, Shc, and c-Mpl. I. Biol. Chem. 270: 4979-4982.

Duan, L., Reddi, A.L., Ghosh, A., Dimri, M., and Band, H. 2004. The Cbl family and other ubiquitin ligases: Destructive forces in control of antigen receptor signaling. Immunity 21: $7-17$.

Duncan, A.W., Rattis, F.M., DiMascio, L.N., Congdon, K.L., Pazianos, G., Zhao, C., Yoon, K., Cook, J.M., Willert, K., Gaiano, N., et al. 2005. Integration of Notch and Wnt signaling in hematopoietic stem cell maintenance. Nat. Immunol. 6: 314-322.

Durand, C., Robin, C., Bollerot, K., Baron, M.H., Ottersbach, K., and Dzierzak, E. 2007. Embryonic stromal clones reveal developmental regulators of definitive hematopoietic stem cells. Proc. Nat1. Acad. Sci. 104: 20838-20843.

Ema, H., Sudo, K., Seita, J., Matsubara, A., Morita, Y., Osawa, M., Takatsu, K., Takaki, S., and Nakauchi, H. 2005. Quantification of self-renewal capacity in single hematopoietic stem cells from normal and Lnk-deficient mice. Dev. Cell 8: 907-914.

Geddis, A.E., Fox, N.E., and Kaushansky, K. 2001. Phosphatidylinositol 3-kinase is necessary but not sufficient for thrombopoietin-induced proliferation in engineered Mplbearing cell lines as well as in primary megakaryocytic progenitors. J. Biol. Chem. 276: 34473-34479.

Göthert, J.R., Gustin, S.E., Hall, M.A., Green, A.R., Göttgens, B., Izon, D.J., and Begley, C.G. 2005. In vivo fate-tracing studies using the Scl stem cell enhancer: Embryonic hematopoietic stem cells significantly contribute to adult hematopoiesis. Blood 105: 2724-2732.

Hock, H., Hamblen, M.J., Rooke, H.M., Schindler, J.W., Saleque, S., Fujiwara, Y., and Orkin, S.H. 2004a. Gfi-1 restricts proliferation and preserves functional integrity of haematopoietic stem cells. Nature 431: 1002-1007.

Hock, H., Meade, E., Medeiros, S., Schindler, J.W., Valk, P.J., Fujiwara, Y., and Orkin, S.H. 2004b. Tel/Etv6 is an essential and selective regulator of adult hematopoietic stem cell survival. Genes \& Dev. 18: 2336-2341.

Ikuta, K. and Weissman, I.L. 1992. Evidence that hematopoietic stem cells express mouse c-kit but do not depend on steel factor for their generation. Proc. Natl. Acad. Sci. 89: 15021506.

Jin, Z., Kirilly, D., Weng, C., Kawase, E., Song, X., Smith, S., Schwartz, J., and Xie, T. 2008. Differentiation-defective stem cells outcompete normal stem cells for niche occupancy in the Drosophila ovary. Cell Stem Cell 2: 39-49.

Kato, Y., Iwama, A., Tadokoro, Y., Shimoda, K., Minoguchi, M., Akira, S., Tanaka, M., Miyajima, A., Kitamura, T., and Na- 
kauchi, H. 2005. Selective activation of STAT5 unveils its role in stem cell self-renewal in normal and leukemic hematopoiesis. J. Exp. Med. 202: 169-179.

Kiel, M.J., Yilmaz, O.H., Iwashita, T., Yilmaz, O.H., Terhorst, C., and Morrison, S.J. 2005. SLAM family receptors distinguish hematopoietic stem and progenitor cells and reveal endothelial niches for stem cells. Cell 121: 1109-1121.

Kim, I., Saunders, T.L., and Morrison, S.J. 2007. Sox17 dependence distinguishes the transcriptional regulation of fetal from adult hematopoietic stem cells. Cell 130: 470-483.

Kimura, S., Roberts, A.W., Metcalf, D., and Alexander, W.S. 1998. Hematopoietic stem cell deficiencies in mice lacking c-Mpl, the receptor for thrombopoietin. Proc. Natl. Acad. Sci. 95: 1195-1200.

Krzemien, J., Dubois, L., Makki, R., Meister, M., Vincent, A., and Crozatier, M. 2007. Control of blood cell homeostasis in Drosophila larvae by the posterior signalling centre. Nature 446: 325-328.

Mancini, S.J., Mantei, N., Dumortier, A., Suter, U., MacDonald, H.R., and Radtke, F. 2005. Jagged1-dependent Notch signaling is dispensable for hematopoietic stem cell self-renewal and differentiation. Blood 105: 2340-2342.

Marteijn, J.A., van der Meer, L.T., Van Emst, L., de Witte, T., Jansen, J.H., and van der Reijden, B.A. 2007. Diminished proteasomal degradation results in accumulation of Gfil protein in monocytes. Blood 109: 100-108.

O'Neil, J. and Look, A.T. 2007. Mechanisms of transcription factor deregulation in lymphoid cell transformation. Oncogene 26: 6838-6849.

Oostendorp, R.A., Robin, C., Steinhoff, C., Marz, S., Bräuer, R., Nuber, U.A., Dzierzak, E.A., and Peschel, C. 2005. Longterm maintenance of hematopoietic stem cells does not require contact with embryo-derived stromal cells in cocultures. Stem Cells 23: 842-851.

Puri, M.C. and Bernstein, A. 2003. Requirement for the TIE family of receptor tyrosine kinases in adult but not fetal hematopoiesis. Proc. Nat1. Acad. Sci. 100: 12753-12758.

Qian, H., Buza-Vidas, N., Hyland, C.D., Jensen, C.T., Antonchuk, J., Mansson, R., Thoren, L.A., Ekblom, M., Alexander, W.S., and Jacobsen, S.E. 2007. Critical role of thrombopoietin in maintaining adult quiescent hematopoietic stem cells. Cell Stem Cell 1: 671-684.

Rathinam, C., Thien, C.B.F., Langdon, W.Y., Gu, H., and Flavell, R.A. 2008. The E3 ubiquitin ligase c-Cbl restricts development and functions of hematopoietic stem cells. Genes \& Dev. (this issue), doi: 10.1101/gad.1651408.

Rizo, A., Vellenga, E., de Haan, G., and Schuringa, J.J. 2006. Signaling pathways in self-renewing hematopoietic and leukemic stem cells: Do all stem cells need a niche? Hum. Mol. Genet. 15: R210-R219. doi: 10.1093/hmg/dd1175.

Rojnuckarin, P., Drachman, J.G., and Kaushansky, K. 1999. Thrombopoietin-induced activation of the mitogen-activated protein kinase (MAPK) pathway in normal megakaryocytes: Role in endomitosis. Blood 94: 1273-1282.

Russell, E.S. 1979. Hereditary anemias of the mouse: A review for geneticists. Adv. Genet. 20: 357-459.

Samokhvalov, I.M., Samokhvalova, N.I., and Nishikawa, S. 2007. Cell tracing shows the contribution of the yolk sac to adult haematopoiesis. Nature 446: 1056-1061.

Seita, J., Ema, H., Ooehara, J., Yamazaki, S., Tadokoro, Y., Yamasaki, A., Eto, K., Takaki, S., Takatsu, K., and Nakauchi, H. 2007. Lnk negatively regulates self-renewal of hematopoietic stem cells by modifying thrombopoietin-mediated signal transduction. Proc. Nat1. Acad. Sci. 104: 2349-2354.

Solar, G.P., Kerr, W.G., Zeigler, F.C., Hess, D., Donahue, C., de Sauvage, F.J., and Eaton, D.L. 1998. Role of c-mpl in early hematopoiesis. Blood 92: 4-10.

Sugiyama, T., Kohara, H., Noda, M., and Nagasawa, T. 2006 Maintenance of the hematopoietic stem cell pool by CXCL12-CXCR4 chemokine signaling in bone marrow stromal cell niches. Immunity 25: 977-988.

Trotman, L.C., Wang, X., Alimonti, A., Chen, Z., Teruya-Feldstein, J., Yang, H., Pavletich, N.P., Carver, B.S., CordonCardo, C., Erdjument-Bromage, H., et al. 2007. Ubiquitination regulates PTEN nuclear import and tumor suppression. Cell 128: 141-156.

Wang, X., Trotman, L.C., Koppie, T., Alimonti, A., Chen, Z., Gao, Z., Wang, J., Erdjument-Bromage, H., Tempst, P., Cordon-Cardo, C., et al. 2007. NEDD4-1 is a proto-oncogenic ubiquitin ligase for PTEN. Cell 128: 129-139.

Wilson, A. and Trumpp, A. 2006. Bone-marrow haematopoieticstem-cell niches. Nat. Rev. Immunol. 6: 93-106.

Yilmaz, O.H., Valdez, R., Theisen, B.K., Guo, W., Ferguson, D.O., Wu, H., and Morrison, S.J. 2006. Pten dependence distinguishes haematopoietic stem cells from leukaemia-initiating cells. Nature 441: 475-482.

Yoshihara, H., Arai, F., Hosokawa, K., Hagiwara, T., Takubo, K., Nakamura, Y., Gomei, Y., Iwasaki, H., Matsuoka, S., Miyamoto, K., et al. 2007. Thrombopoietin/MPL signaling regulates hematopoietic stem cell quiescence and interaction with the osteoblastic niche. Cell Stem Cell 1: 685-697.

Zhang, J., Niu, C., Ye, L., Huang, H., He, X., Tong, W.G., Ross, J., Haug, J., Johnson, T., Feng, J.Q., et al. 2003. Identification of the haematopoietic stem cell niche and control of the niche size. Nature 425: 836-841. 


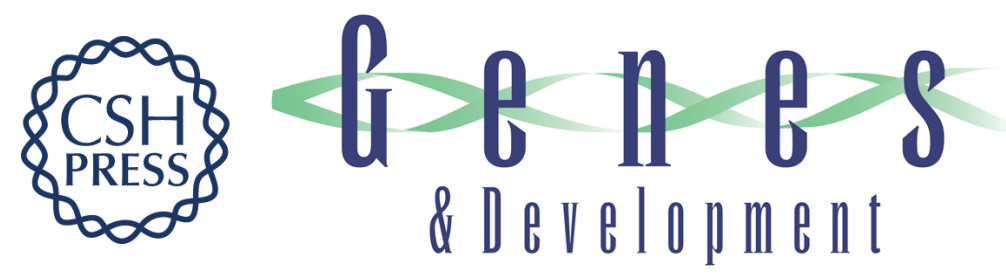

\section{Fine-tuning of hematopoietic stem cell homeostasis: novel role for ubiquitin ligase}

Tomomasa Yokomizo and Elaine Dzierzak

Genes Dev. 2008, 22:

Access the most recent version at doi:10.1101/gad.1669908

\section{Related Content The E3 ubiquitin ligase c-Cbl restricts development and functions of hematopoietic stem cells \\ Chozhavendan Rathinam, Christine B.F. Thien, Wallace Y. Langdon, et al. Genes Dev. April , 2008 22: 992-997 \\ References This article cites 46 articles, 18 of which can be accessed free at: http://genesdev.cshlp.org/content/22/8/960.full.html\#ref-list-1 \\ Articles cited in: \\ http://genesdev.cshlp.org/content/22/8/960.full.html\#related-urls \\ License \\ Email Alerting \\ Receive free email alerts when new articles cite this article - sign up in the box at the top Service right corner of the article or click here.}

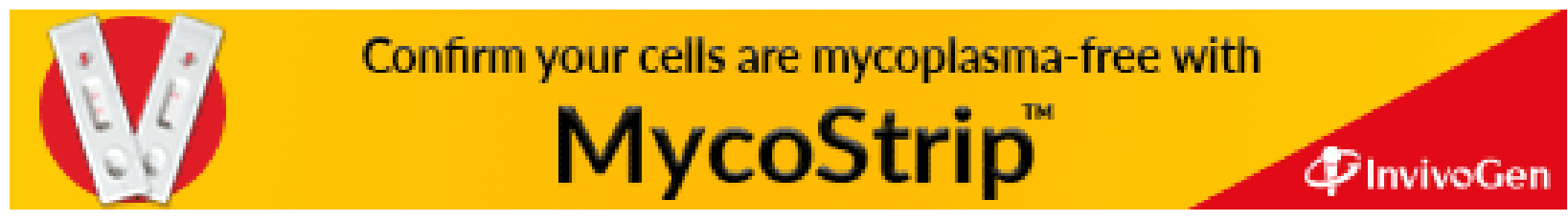

